\title{
Transcriptomics reveals Granulosa Cells Coping through Redox, Inflammatory, Metabolic and Cytoskeleton Mechanisms under Acute Heat Stress
}

\author{
Abdul Sammad ${ }^{1}$, Hanpeng Luo ${ }^{1}$, Lirong Hu ${ }^{1}$, Huabin $\mathrm{Zhu}^{2, *}$ and Yachun Wang ${ }^{1, *}$ \\ 1 National Engineering Laboratory for Animal Breeding, Key Laboratory of Animal Genetics, Breeding and \\ Reproduction, MARA, College of Animal Sciences and Technology, China Agricultural University, 100193 \\ Beijing, China \\ 2 Embryo Biotechnology and Reproduction Laboratory, Institute of Animal Sciences, Chinese Academy of \\ Agricultural Sciences, 100193, Beijing, China \\ * Correspondence: zhuhuabin@caas.cn (H.Z.); wangyachun@cau.edu.cn (Y.W.)
}

\begin{abstract}
Heat stress affects the granulosa cells (GCs) and ovarian follicular microenvironment, causing poor oocyte developmental competence and fertility. This study aims to investigate the physical responses and global transcriptomic changes in bovine GCs to acute heat stress $\left(43^{\circ} \mathrm{C}\right.$ for $2 \mathrm{~h}$ ) in-vitro and give essential insights into the general interaction at cell-stress nexus. Heat-stressed GCs exhibited transient proliferation senescence, resumed proliferation at $48 \mathrm{~h}$ post-stress. While post-stress immediate culture-media change had a relatively positive effect on proliferation resumption. Increased accumulation of reactive oxygen species and apoptosis was observed in heat stress group. In spite of the upregulation of inflammatory, pro-apoptotic and caspase executioner genes, antioxidants and anti-apoptotic genes were also upregulated in heat-stressed GCs. Progesterone and Estrogen hormones along with steroidogenic genes expression, declined significantly, in spite of the upregulation of genes involved in cholesterol synthesis. Out of 12385 differentially expressed genes (DEGs), 330 significant DEGs (75 upregulated, 225 downregulated) were subjected to KEGG functional pathway annotation, gene ontology enrichment, and STRING network analyses. Based on the manual query of DEGs, pathway and enrichment analyses, a vast interplay observed among all major signaling pathways strongly evidence the repression of cellular transcriptional and proliferation activity, averting the effects of heat stress through remodeling of cellular structural proteins and energetic-homeostasis. This study presents detailed responses of acute heat-stressed GCs at physical, transcriptional, and pathway levels and presents interesting insights into future studies regarding GCs adaptation and their interaction with oocyte and reproductive system at ovarian level.
\end{abstract}

Keywords: granulosa cells; heat stress; apoptosis; oxidative stress; RNA-seq; transcriptomics; differentially expressed genes; signaling pathways

\section{Introduction}

Events of heat waves are common in tropical, subtropical, and even in temperate zones due to climate change associated global warming [1]. Heat stress poses challenges to Agricultural production and thus the food security [2], general health and well-being [3], and sustainable dairy production [4-6]. Ambient temperature exceeding $25^{\circ} \mathrm{C}$ causes heat stress in mammals including cattle $[7,8]$. Whereas high temperature in the range of $35-40{ }^{\circ} \mathrm{C}$ causes enormous alterations in physiology and biochemistry of the body [8-11]. Heat stress associated biochemical changes in the reproduction system of cattle leads to delayed conception and low fertility rates [12-14]. 
Granulosa cells are the integral component of the ovaries, where they tend to nourish the developing embryo inside the follicle and regulate the endocrine signals of the reproductive at ovarian axis $[15,16]$. Heat stress is shown to markedly decrease the survival rate of bovine granulosa cells (GCs), increase oxidative stress, limit cell proliferation and transition process, inhibit steroidogenesis and promote GCs apoptosis [17-19]. Impairment of GCs through various external or internal stress stimuli may compromise the ovarian functions and development competence of oocytes [20,21]. In a previous study, higher ambient temperatures and associated heat stress is shown to associate with a decline in ovarian reserves and symptoms reproductive aging in the women [22]. In particular, pre-ovulation stage of ovarian follicle remain highly susceptible to the adverse effect of heat stress causing oxidative stress and damage to the developing oocyte [23-25]. Heat stress causes energetic metabolism alterations in the body [26] and resulting high non-esterified fatty acids (NEFA), ketones, and inflammatory cytokines alters the biochemical profile of the ovarian follicles [13,25,27-29]. These biochemical and inflammatory changes causes dysfunction of GCs and leads to developmental competence of the oocytes [25,30,31].

Transcriptomic level studies involving global RNA-sequencing may give essential biological insights into the cellular mechanisms, metabolic level changes and apoptotic and antioxidant pathways [18]. Earlier studies have reported a senescence in proliferation and reported variable ability of camelid GCs to recover their proliferation potential following acute and chronic heat stress exposures [32,33]. In our previous study about GCs [18], there was a disparity among different temperature ranges where $41^{\circ} \mathrm{C}$ presented less lethality than $40{ }^{\circ} \mathrm{C}$. Therefore, it was imperative to evaluate the physiological and transcriptome level changes in the acute heat-stressed GCs. Henceforth, this study selected 43 ${ }^{\circ} \mathrm{C}$ at the rate of $2 \mathrm{~h} \mathrm{[34]} \mathrm{to} \mathrm{inflict} \mathrm{acute} \mathrm{heat} \mathrm{stress} \mathrm{to} \mathrm{GCs.} \mathrm{To} \mathrm{the} \mathrm{best} \mathrm{of} \mathrm{our} \mathrm{knowledge,}$ there is a lack of systematic transcriptomic study of granulosa cell culture in response to acute heat stress $\left(43^{\circ} \mathrm{C}\right)$. We hypothesize that GCs under acute heat stress would exhibit physical insults and undergo extensive changes in biological pathways funneled towards the cellular homeostasis mechanisms.

\section{Methods}

\subsection{Granulosa cells culture and heat treatment}

Healthy ovaries from regularly cycling cows collected in physiological normal saline were washed with phosphate buffer saline (PBS). Follicular contents were collected from small follicles (3-8 $\mathrm{mm}$ ) through 18-gauge syringe, sieved through a $40 \mu \mathrm{m}$ filter (Corning Inc., Corning, NY, USA), followed by centrifugation at 1,500 rpm for $5 \mathrm{~min}$. Supernatant follicular fluid was discarded, and the GCs pellet was washed 2 times with warm PBS containing $1 \%$ antibiotics. GCs were seeded $\left(2 \times 10^{6}\right.$ per well $)$ in 6 -well sterile culture plates (Corning Inc., Corning, NY, USA). Culture media consisting DMEM/F12 medium (Dulbecco's Modified Eagle Medium/F-12 Hem; Thermo Fisher Scientific, Waltham, MA, USA) containing 10\% FBS (Fetal Bovine Se-rum; Thermo Fisher Scientific, Waltham, MA, USA) and $1 \%$ antibiotic was supplemented, and cultured under $38{ }^{\circ} \mathrm{C}$ and $5 \% \mathrm{CO} 2$ (Carbon dioxide) in humidified cell incubator. Culture medium was changed after $24 \mathrm{~h}, 80 \%$ confluence was obtained at $36 \mathrm{~h}$, after which GCs fasted with reduced FBS (2\%) media for $12 \mathrm{~h}$. GCs were cultured in a fresh original culture medium for an additional $6 \mathrm{~h}$ at $48 \mathrm{~h}$ and afterwards subjected to $2 \mathrm{~h}$ of acute heat stress $\left(43^{\circ} \mathrm{C}\right)$, while control group was kept at 38 ${ }^{\circ} \mathrm{C}$. 


\subsection{Cell proliferation assay}

Cells $\left(2 \times 10^{4}\right.$ in each well) were cultured in 96-well plates and optical density (OD) was measured using Cell Counting Kit-8 (CCK-8; Dojindo Laboratories, Kumamoto, Japan) according to the manufacturer instructions. In brief, $10 \mu \mathrm{L}$ of CCK- 8 was added to each well and an optimized incubation time of $2 \mathrm{~h}$ was used for all measurements. The absorbance of cells was immediately (after heat stress) measured at $450 \mathrm{~nm}$ wavelength by a plate reader, and afterward at the intervals of $6,12,24,48,72,96$, and $144 \mathrm{~h}$. Absorbance measurements were also synchronous with control group measurements. For the immediate CCK- 8 assay ( $0 \mathrm{~h}$ after heat stress), CCK- 8 solution was added before the commencement of heat stress treatment.

\subsection{Reactive oxygen species, apoptosis, and hormone measurements}

Cells were cultured in a clear bottom 96-well black plates (Corning Inc., Corning, NY, USA) and fluorescence OD was measured using a 6-carboxy-2', 7'-dichloro-dihydro-fluorescein diacetate kit (DCFDA kit, Abcam, Cambridge, MA, USA) according to the manufacturer instructions. Briefly, cells $\left(1 \times 10^{4}\right.$ in each well) were initially cultured in a clear bottom 96-well black plates (Corning Inc., Corning, NY, USA), as described earlier. The medium was removed and wells were washed once with $100 \mu \mathrm{L} /$ well of $1 \times$ Buffer (supplied in kit) followed by the addition of $100 \mu \mathrm{L} /$ well of the $20 \mu \mathrm{M}$ DCFDA solution. Cells were incubated for $40 \mathrm{~min}$ at $38{ }^{\circ} \mathrm{C}$ in the dark. After that, DCFDA solution was removed and cells were supplemented with $100 \mu \mathrm{L} /$ well complete culture medium and incubated for $8 \mathrm{~h}$ (heat stress group, $2 \mathrm{~h}$ at $43^{\circ} \mathrm{C}$ followed by 6 hours at $38^{\circ} \mathrm{C}$ ). After $8 \mathrm{~h}$ of incubation, fluorescence OD was immediately measured on infinite M200 PRO (Tecan Deutschland $\mathrm{GmbH}$, Crailsheim, BW, Germany) fluorescence plate reader at excitation/emission = 485/535 nm wavelength.

The qualitative apoptosis rate of GCs was assessed by fluorescence microscope with an Annexin V-FITC kit (Nanjing Jiancheng Bio Inst., Nanjing, China). After post heat stress recovery at $38{ }^{\circ} \mathrm{C}$, cells were harvested by $0.25 \%$ trypsin and washed twice with warm PBS and then added $500 \mu \mathrm{L} 1 \times$ binding buffer. Subsequently, $5 \mu \mathrm{L}$ FITC and PI were added to each replicate. After $20 \mathrm{~min}$ incubation at room temperature, slides were prepared and observed under a fluorescence microscope (Axio Imager A2; ZEISS Microscopy, Oberkochen, BW, Germany). Fluorescence microscope pictures at $40 \times$ of early apoptotic (green) and late apoptotic (red) cells were recorded. Four replicate slides of each were counted for distinct red and green features.

After $6 \mathrm{~h}$ of heat stress treatment, the culture media from both groups were collected and stored at $-80^{\circ} \mathrm{C}$ for the determination of $\mathrm{P} 4$ and $\mathrm{E} 2$ concentration through a commercial ELISA kit (Cusabio Technology LLC, Wuhan, Hubei, China) according to manufacturer protocols. The absorbance was measured by an Infinite M200 PRO (Tecan Deutschland $\mathrm{GmbH}$, Crailsheim, BW, Germany) plate reader at $450 \mathrm{~nm}$ wavelength.

\subsection{Statistical analysis of physiological parameters}

The data from at least six replicates each for cell proliferation, ROS, and apoptosis measurements were analyzed using IBM SPSS (Statistical Package for Social Sciences software version 26.0, Armonk, NY, USA). Analysis of variance was performed, and means were compared using Tukey's honestly significant difference (HSD) test at a 5\% level of significance $(\alpha=0.05)$. All the data represented in the figures are expressed as mean \pm standard error (S.E).

\subsection{RNA sequencing}

The RNA was isolated from GCs according to the manufacturer's instructions of TRIzol Reagent method [35]. RNA quality and concentration was assessed using Equalbit RNA BR Assay Kit (Invitrogen, California, USA) and Nanodrop 2000 (Thermo, Massachusetts, USA). RNA integrity was detected by $1 \%$ agarose gel electrophoresis, and it could be used for library construction with 28S/18S $>1$. For RNA-seq library, a total of $2 \mu \mathrm{g}$ RNA 
was used for purification and fragment using NEBNext Poly(A) mRNA Magnetic Isolation Module (Cat No. E7490S, New England Biolabs (UK) Ltd., Hitchin, Herts, UK) then followed by cDNA library with NEBNext Ultra RNA Library Prep Kit for Illumina (Cat No. E7530S, New England Biolabs (UK) Ltd., Hitchin, Herts, UK). Libraries were quantified by Equalbit RNA BR Assay Kit (Invitrogen, California, USA) and pooled equimolarly, finally submitted for sequencing by NovaSeq 6000 System (Illumina, Inc., San Diego, Californi, USA) which generated 150 bases paired-end reads.

\subsection{Differential expression and functional analyses of differentially expressed genes}

The quality of the sequencing reads was evaluated by FastQC software (v0.11.9), and global trimming carried using the Fastp (v0.20.0) [36]. All clean reads were mapped to the bovine genome of version ARS-UCD1.2 using the software package STAR (v2.7.5c), and Picard query (http://broadinstitute.github.io/picard/) was carried out to mark duplicates. We investigated the counts of gene expression through the RNA-SeQC software (v2.3.6) Principal component analysis and clustering structure were performed by using the psych and hcluster R packages. For differential expression genes (DEGs) screening, the quantileadjusted conditional maximum likelihood (qCML) was performed using edgeR in R package [37] with criteria fold change $\geq 1.5$ and 0.05 for the alpha of false discovery rate (FDR; 3 samples in treatment group versus 3 samples in control group). The DEGs were subjected to Kyoto Encyclopedia of Genes and Genomes (KEGG) pathway and enrichment analysis of Gene Ontology (GO). Online DAVID software (https://david.ncifcrf.gov/) was used for functional annotation DEGs of the GO terms including biological process (BP), cellular component (CC), and molecular function (MF) enrichment analysis. STRING version 11.5 (https://cn.string-db.org/) was used for the protein-protein interaction (PPI) network analysis of DEGs.

\section{Results}

\subsection{Influence of heat stress on physical parameters of bovine granulosa cells}

Cultured GCs were exposed to heat stress treatment $\left(43^{\circ} \mathrm{C}\right)$ in-vitro, while control group remained at $38^{\circ} \mathrm{C}$. Cells in the control group maintained steady proliferation activity (Figure 1A). No change in cell viability was observed until $24 \mathrm{~h}$ after heat stress exposure (Figure 1B), while the group with medium change at $0 \mathrm{~h}$ after heat stress (Figure 1C) did show certain degree of proliferation activity. Both control and heat stress groups achieved confluences at $72 \mathrm{~h}$ after treatment.
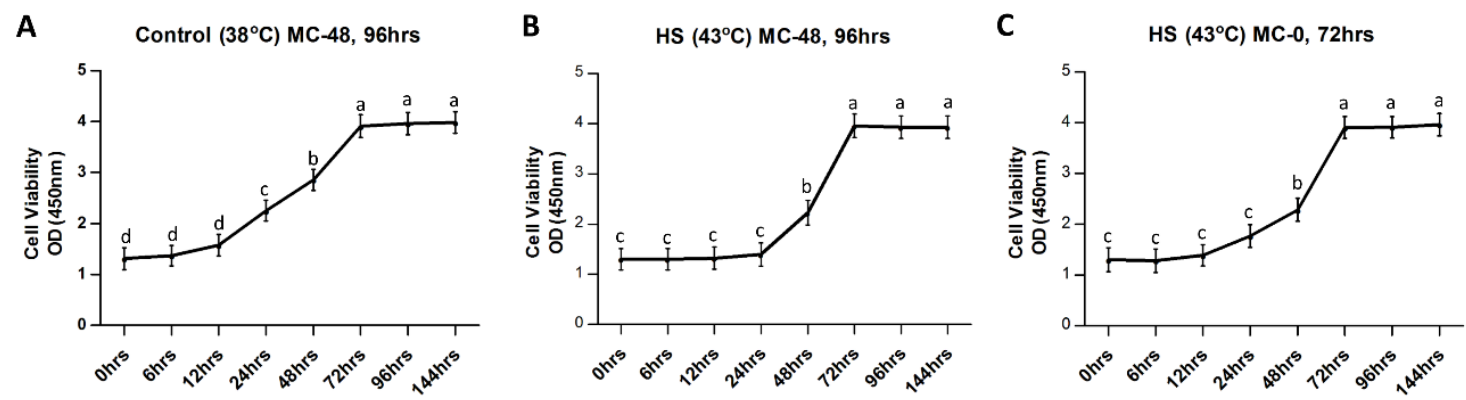

Figure 1. Comparison of physical parameters of bovine granulosa cells (GCs) exposed to heat stress $\left(43^{\circ} \mathrm{C}\right.$ for $\left.2 \mathrm{~h}\right)$ versus control $\left(38^{\circ} \mathrm{C}\right)$. GCs proliferation curves with mean optical densities (OD) measured at 450nm wavelength are plotted against different recovery time points in hours (hrs) for control (A) and heat stress group (B, C). "MC" indicates culture media change at $48 \mathrm{~h}$ and $96 \mathrm{~h}$ in $1 \mathrm{~A}$ and $1 \mathrm{~B}$, while $0 \mathrm{~h}$ (immediately after completion of heat stress in-vitro) and $72 \mathrm{~h}$ for 1C. Each panel without common letters is significantly different $(p<0.05)$.

GCs were subjected to post treatment exposure recovery for $6 \mathrm{~h}$ at $38^{\circ} \mathrm{C}$, after which GCs ROS and apoptosis was estimated. Compared to the control group, significant $(p$ $<0.05$ ) increase in ROS level was observed in the heat stress treatment group (Figure 2D). 
Heat stressed GCs had significantly higher $(p<0.05)$ apoptotic rate compared to the control group (Figure 1C), as shown in representative florescent microphotographs of early apoptotic and late apoptotic events in control group (Figure 1A) and heat stress (Figure 1B), respectively. Similarly, P4 and E2 concentration was significantly $(p<0.05)$ decreased in the culture media of the treatment group (Figure $1 \mathrm{E}$ and $1 \mathrm{~F}$, respectively).

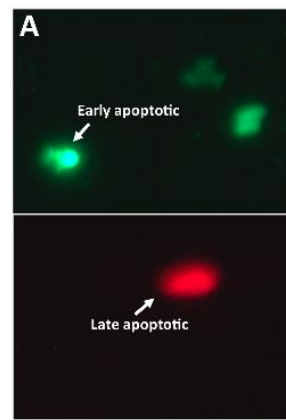

D

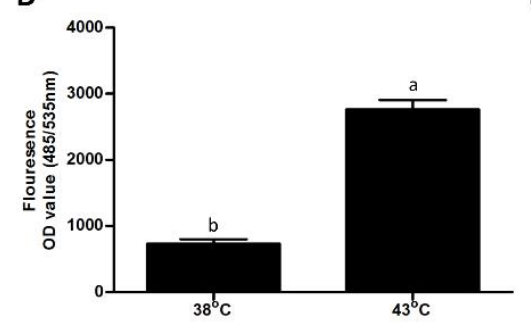

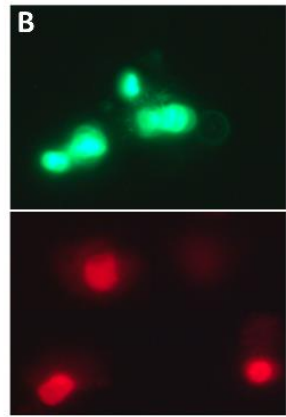

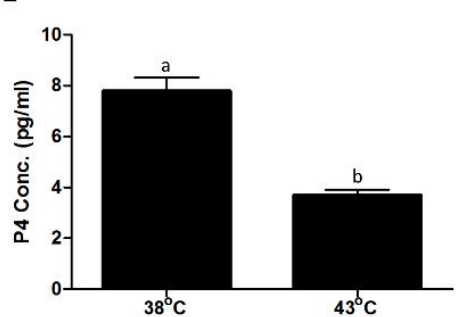

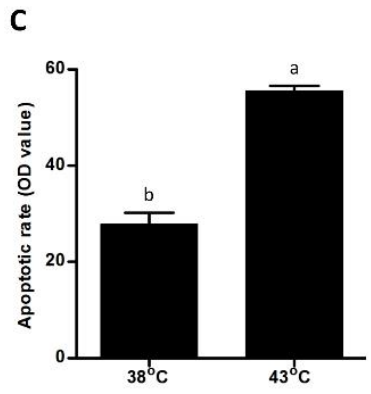

F

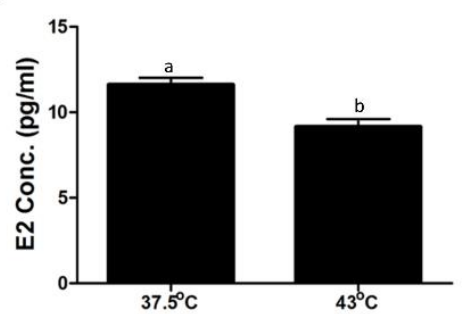

Figure 2. Comparison of physical parameters of bovine granulosa cells (GCs) exposed to heat stress $\left(43^{\circ} \mathrm{C}\right.$ for $2 \mathrm{~h}$ ) versus control $\left(38^{\circ} \mathrm{C}\right)$. Representative fluorescence microscope pictures $(200 \times)$ of late apoptotic (red) and early apoptotic (green) cells after staining with FITC/PI dye for control (A) and heat stress treatment (B) groups. Means comparison of apoptotic rate (sum of red and green events) of GCs under control and heat stress (C). Reactive oxygen species (ROS) through fluorescence OD value (measured at 485/535nm wavelength) of GCs stained with 2', $7^{\prime}$-dichlorofluorescine diacetate (DCFDA), is shown on the $y$-axis, and the temperature treatments are indicated on the $x$-axis (D). Progesterone (P4) and Estrogen (E2) concentration change comparison among control and heat stress group (E and F, respectively). Data are represented as mean \pm S.E. of at least three independent cultures with further at least three replicates for each culture. Each panel without common letters is significantly different $(p<0.05)$.

\subsection{Role of acute heat stress on GCs through deep sequencing}

RNA-seq read counts of heat stress and control groups (3 replicate each) were distinctly different from each other as determined through principal components analysis and dendrogram clustering structure (Supplementary Figure S1). Whole-genome expression profiling with RNA-Sequencing analysis revealed that heat stress had a significant effect on the gene expression in GCs. Out of 12385 differentially expressed genes (DEGs) listed in Supplementary table S1, total 330 genes were identified as significant DEGs with fold change of $\geq 1.5$ and FDR $<0.05$. Among these DEGs, 75 were up-regulated and 255 were down-regulated genes (Figure 3). Top 20 upregulated and downregulated significant DEGs are listed below in Table 1. Where majority of DEGs are involved in cellular stress response, structural remodeling, and cellular reprogramming. 

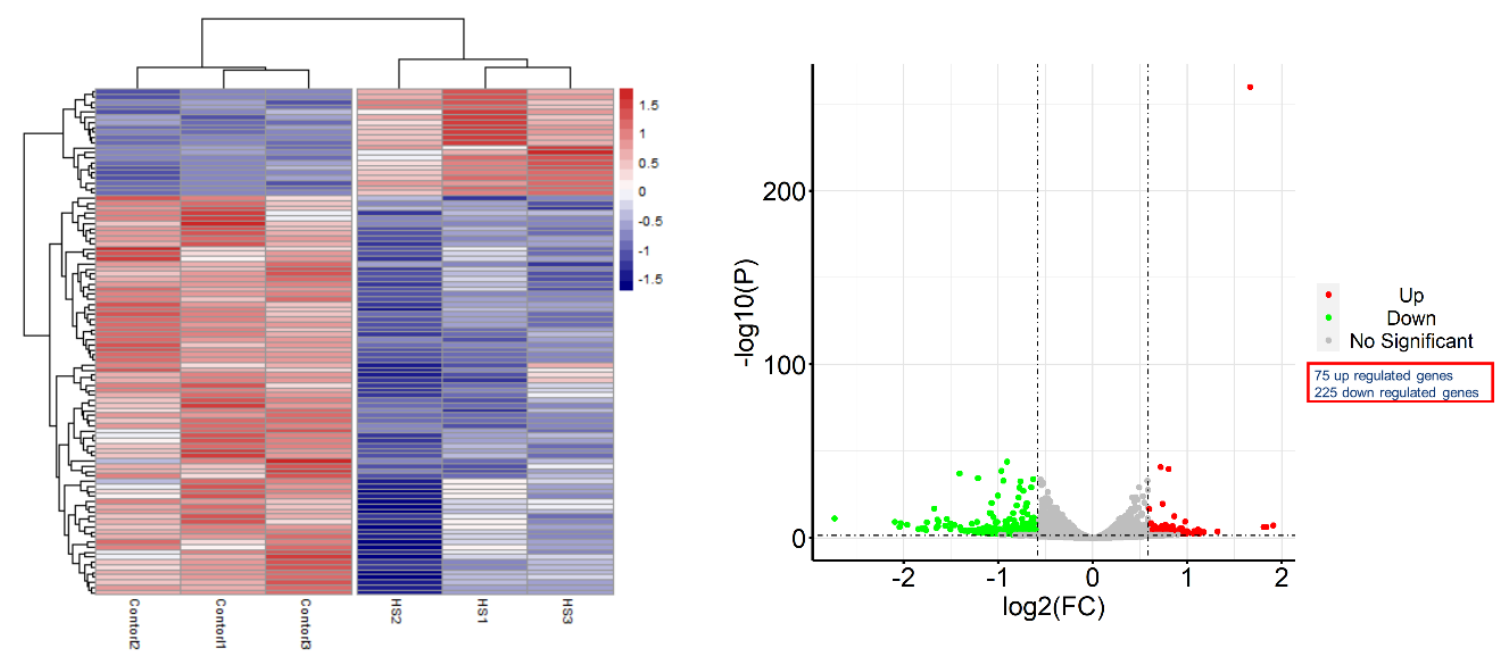

Figure 3. Heatmap for the figure hierarchical cluster analysis of significant differentially expressed genes (DEGs) between heat stress $(n=3)$ and control $(n=3)$ group of granulosa cells $(3 A)$. Volcano plot of DEGs between heat stress $(n=3)$ and control $(n=3)$ group $(3 B)$. Red represents upregulated genes and blue represents down-regulated genes (FC $\geq 1.5$ and FDR $<0.05)$.

Table 1. Detailed list of top 20 upregulated and downregulated significant differentially expressed genes (DEGs) between heat stress $(n=3)$ and control $(n=3)$ group of granulosa cells (GCs).

\begin{tabular}{|c|c|c|c|c|}
\hline DEGs & $\log \mathrm{FC}$ & $\log C P M$ & FDR & Description \\
\hline RBM3 & 1.66 & 8.16 & $2 \mathrm{E}-256$ & RNA binding motif protein 3 \\
\hline GREM1 & 0.72 & 6.91 & $5 \mathrm{E}-38$ & "gremlin 1, DAN family BMP antagonist" \\
\hline ACTA2 & 0.80 & 7.10 & $5 \mathrm{E}-37$ & "actin alpha 2, smooth muscle" \\
\hline IFI27 & 0.74 & 5.16 & $6 \mathrm{E}-18$ & putative ISG12(a) protein \\
\hline$L C P 1$ & 0.60 & 5.67 & $4 \mathrm{E}-15$ & lymphocyte cytosolic protein 1 \\
\hline ARHGDIB & 0.86 & 3.50 & $5 \mathrm{E}-11$ & Rho GDP dissociation inhibitor beta \\
\hline IQCK & 0.98 & 2.54 & $4 \mathrm{E}-08$ & IQ motif containing $\mathrm{K}$ \\
\hline PCSK1 & 0.62 & 3.98 & 2E-07 & proprotein convertase subtilisin/kexin type 1 \\
\hline DTL & 0.61 & 3.74 & $8 \mathrm{E}-07$ & denticleless E3 ubiquitin protein ligase homolog \\
\hline ADH6 & 0.77 & 3.04 & $1 \mathrm{E}-06$ & alcohol dehydrogenase 6 (class V) \\
\hline PYGM & 1.91 & 0.08 & $3 \mathrm{E}-06$ & "glycogen phosphorylase, muscle associated" \\
\hline C3AR1 & 0.75 & 2.90 & $4 \mathrm{E}-06$ & complement C3a receptor 1 \\
\hline PREX2 & 0.84 & 3.25 & $5 \mathrm{E}-06$ & $\begin{array}{l}\text { phosphatidylinositol-3,4,5-trisphosphate dependent Rac-exchange fac- } \\
\text { tor } 2\end{array}$ \\
\hline HERC5 & 0.73 & 3.17 & $6 \mathrm{E}-06$ & HECT and RLD domain containing E3 ubiquitin protein ligase 5 \\
\hline SPARCL1 & 0.66 & 3.38 & 7E-06 & SPARC like 1 \\
\hline AOX1 & 0.64 & 3.64 & $1 \mathrm{E}-05$ & aldehyde oxidase 1 \\
\hline ADAMTS20 & 1.81 & 0.24 & 2E-05 & ADAM metallopeptidase with thrombospondin type 1 motif 20 \\
\hline KASH5 & 1.84 & 0.33 & 2E-05 & KASH Domain Containing 5 \\
\hline LOXL4 & 0.80 & 2.89 & 2E-05 & lysyl oxidase like 4 \\
\hline CDKN2A & 0.67 & 3.42 & 3E-05 & cyclin dependent kinase inhibitor $2 \mathrm{~A}$ \\
\hline LENG8 & -0.91 & 7.45 & $6 \mathrm{E}-41$ & leukocyte receptor cluster member 8 \\
\hline DCHS1 & -0.97 & 5.88 & $5 \mathrm{E}-36$ & dachsous cadherin-related 1 \\
\hline CCDC136 & -1.21 & 4.19 & $6 \mathrm{E}-32$ & coiled-coil domain containing 136 \\
\hline PLXNA2 & -0.63 & 6.69 & $2 \mathrm{E}-31$ & plexin $\mathrm{A} 2$ \\
\hline MPPE1 & -0.95 & 5.00 & $1 \mathrm{E}-30$ & metallophosphoesterase 1 \\
\hline TBX18 & -0.65 & 6.37 & $5 \mathrm{E}-27$ & T-box transcription factor 18 \\
\hline SMAD6 & -0.78 & 5.61 & $1 \mathrm{E}-26$ & SMAD family member 6 \\
\hline$A B C C 5$ & -0.74 & 5.41 & $4 \mathrm{E}-25$ & ATP binding cassette subfamily $\mathrm{C}$ member 5 \\
\hline SCN9A & -1.00 & 4.03 & $2 \mathrm{E}-22$ & sodium voltage-gated channel alpha subunit 9 \\
\hline RSRP1 & -1.07 & 4.17 & $2 \mathrm{E}-18$ & arginine and serine rich protein 1 \\
\hline CROCC & -0.70 & 5.30 & 3E-18 & "ciliary rootlet coiled-coil, rootletin" \\
\hline EFNB2 & -0.81 & 4.55 & $5 \mathrm{E}-17$ & ephrin B2 \\
\hline VEGFA & -0.71 & 8.52 & $3 \mathrm{E}-16$ & vascular endothelial growth factor A \\
\hline DTX4 & -1.68 & 1.96 & $3 \mathrm{E}-15$ & deltex E3 ubiquitin ligase 4 \\
\hline$K L F 7$ & -0.74 & 4.37 & $2 \mathrm{E}-13$ & Kruppel like factor 7 \\
\hline SEL1L3 & -0.73 & 4.70 & $2 \mathrm{E}-13$ & SEL1L family member 3 \\
\hline
\end{tabular}




\begin{tabular}{ccccc}
\hline PPP1R12B & -0.84 & 3.81 & $7 \mathrm{E}-13$ & protein phosphatase 1 regulatory subunit 12B \\
RGS9 & -1.09 & 3.03 & $9 \mathrm{E}-13$ & regulator of $\mathrm{G}$ protein signaling 9 \\
KIFC2 & -0.69 & 4.63 & $3 \mathrm{E}-12$ & kinesin family member $\mathrm{C} 2$ \\
GABBR1 & -0.63 & 4.31 & $2 \mathrm{E}-10$ & gamma-aminobutyric acid type B receptor subunit 1 \\
\hline
\end{tabular}

FDR; false discovery ratio.

Among the several hundred genes up or downregulated as a result of in-vitro acute heat stress (Supplementary table S2), an effort was made to filter out genes related to; heat shock protein family, apoptosis, antioxidants support, energetic support (Figure 4), and partial clue of major signaling pathways on the basis of extensive manual query of these pathways related literature (Figure 5).
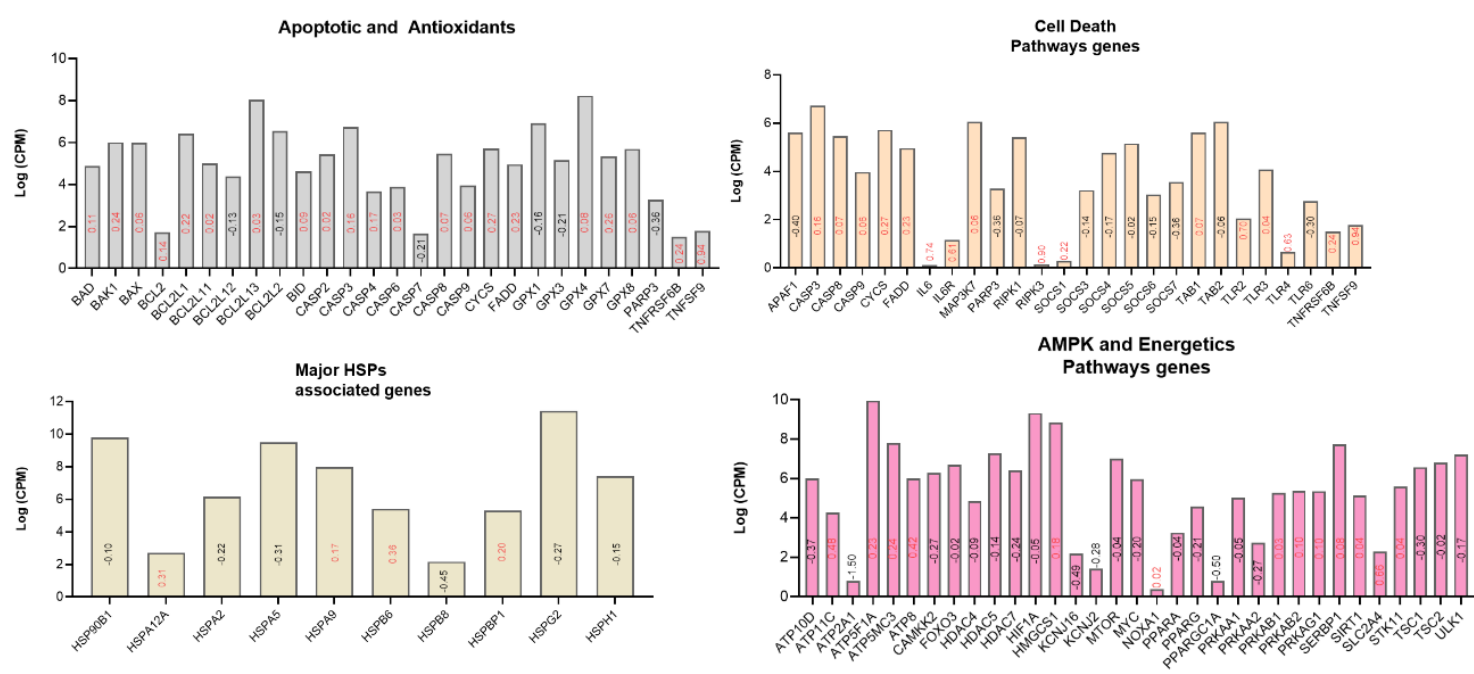

Figure 4. Bar charts based on the manual query of the differentially expressed genes. Various anti apoptotic, antioxidant, inflammation, cell damage, chaperones, and cellular energetic support associated genes are given. Where $y$-axis represents log of counts per million, log of fold change is presented inside the bars (red upregulated and black downregulated) against respective genes on $\mathrm{x}$-axis.
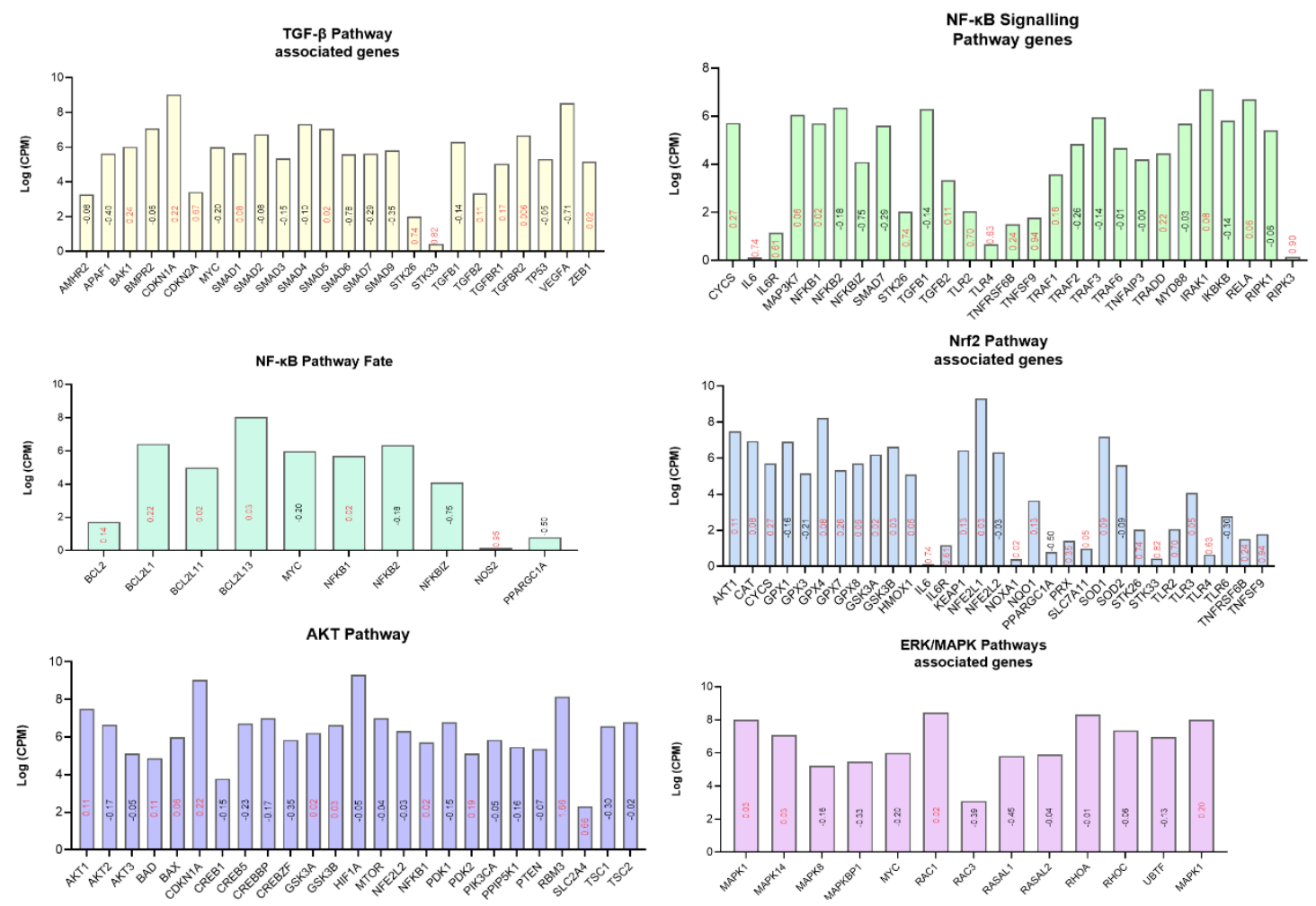
Figure 5. Bar charts based on the manual query of the differentially expressed genes (DEGs). Various important pathways, as presented by the title of the bars charts and associated genes are shown. Where $y$-axis represents log of counts per million, log of fold change is presented inside the bars (red upregulated and black downregulated) against respective genes on x-axis.

\subsection{Pathway analysis of differentially expressed genes}

Detailed results of KEGG based pathway analysis of the DEGs are given in Supplementary table S3. While the illustration of all canonical pathways $(p<0.05)$ is given in Figure 6. Additionally, supplementary table S3 was checked for the top enriched genes in each pathway, and are listed along with enrichment ratios (in all pathways) in Table 2.

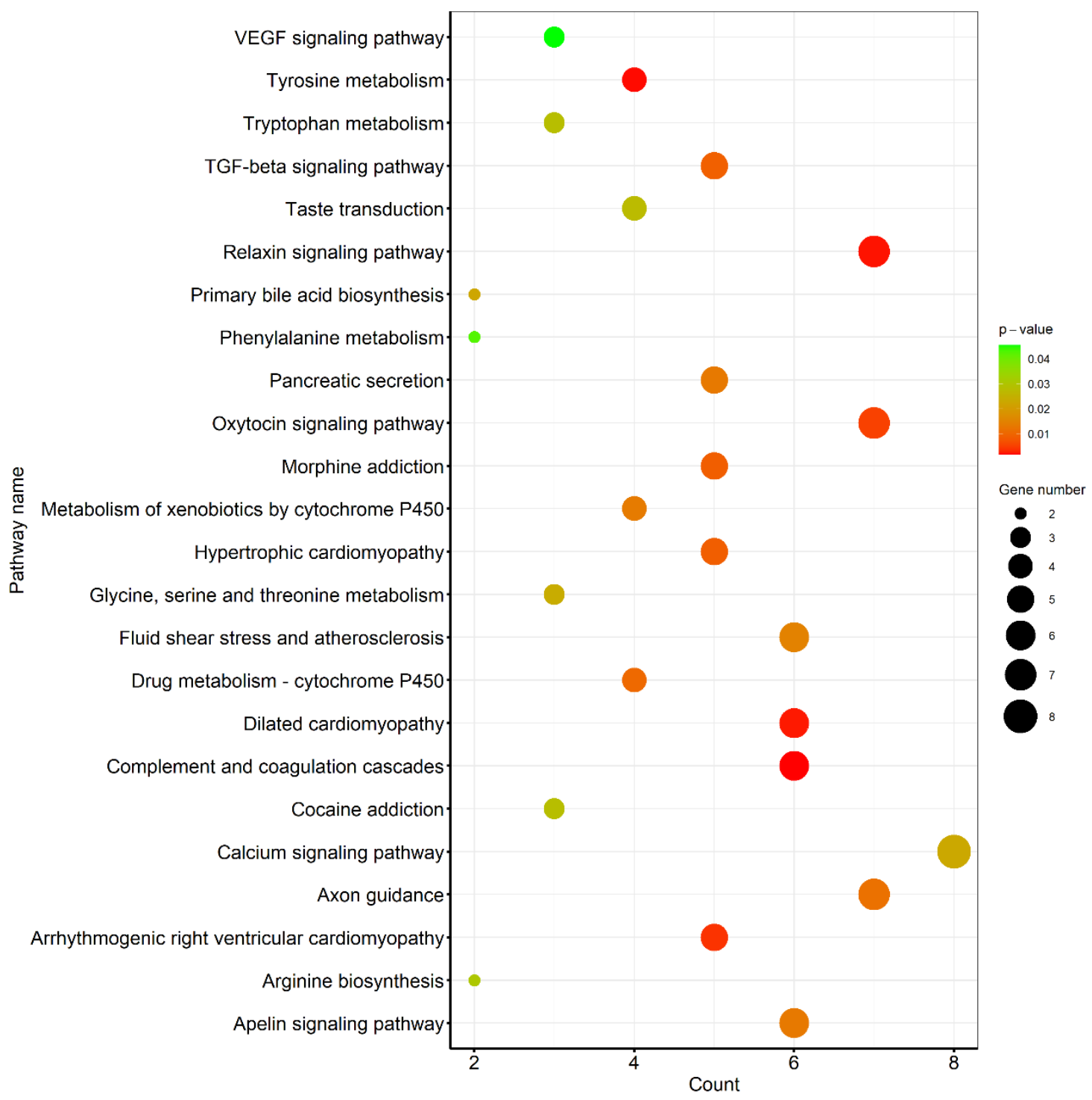

Figure 6. Kyoto encyclopedia of genes and genomes (KEGG) based pathway analysis of differentially expressed genes (DEGs) in response to heat stress granulosa cells: All the significantly $(p<0.05)$ regulated pathways and DEGs enrichment ratios are illustrated.

Table 2. Pathway analysis of differentially expressed genes in response to heat stress was checked for top 10 DEGs abundantly enriched in various pathways are listed along with their statistics details and descriptions.

\begin{tabular}{cccccc}
\hline Genes & E. R. & $\operatorname{logFC}$ & $\log$ CPM & $p$-value & Description \\
\hline$A D C Y 2$ & 7 & -0.73 & 2.83 & $2 \mathrm{E}-05$ & adenylate cyclase 2 \\
$R Y R 2$ & 7 & -0.88 & 1.33 & $3 \mathrm{E}-03$ & ryanodine receptor 2 \\
$M A O B$ & 6 & -0.82 & 1.47 & $4 \mathrm{E}-03$ & monoamine oxidase B \\
\hline
\end{tabular}




\begin{tabular}{cccccc}
\hline ATP2A1 & 5 & -1.50 & 0.80 & 3E-07 & ATPase sarcoplasmic Ca ${ }^{2+}$ transporting 1 \\
VEGFA & 4 & -0.71 & 8.52 & $3 \mathrm{E}-16$ & vascular endothelial growth factor A \\
CACNB1 & 4 & -0.81 & 3.07 & $8 \mathrm{E}-07$ & Ca $^{2+}$ voltage-gated channel subunit beta 1 \\
GNB3 & 4 & -0.91 & 1.09 & $5 \mathrm{E}-03$ & G protein subunit beta 3 \\
NOS2 & 4 & 0.95 & 0.16 & $2 \mathrm{E}-02$ & nitric oxide synthase 2 \\
AOC2 & 3 & -0.91 & 1.68 & $2 \mathrm{E}-04$ & amine oxidase copper containing 2 \\
KDR & 3 & -1.05 & 0.02 & $1 \mathrm{E}-02$ & kinase insert domain receptor \\
\hline
\end{tabular}

E.R., enrichment ratio in separate KEGG pathways.

Based on Figure 4, Figure 5, and manual search of given pathways in stress associated literature and molecular signaling mechanisms given in those studies, supplementary table S1 was check for genes regulation and flowcharts were drawn. Flow charts consisting of various integral cellular pathways and associated genes involved in initiation, intermediate signaling, direct or indirect triggering, target and outcome, and inhibitory mechanisms are given (Figure 5).

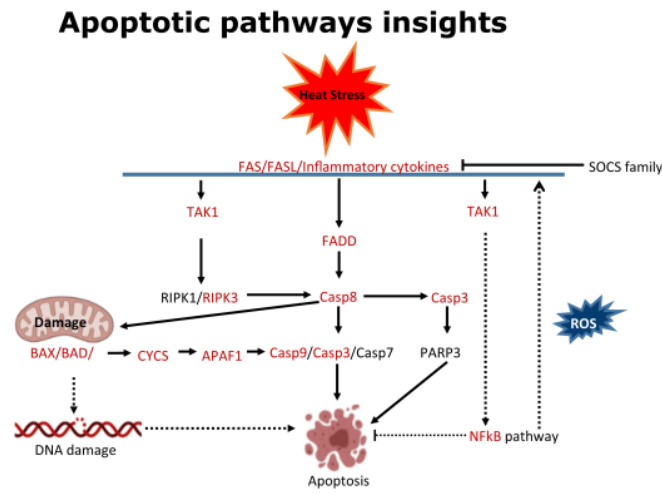

NF-KB signaling pathway insights
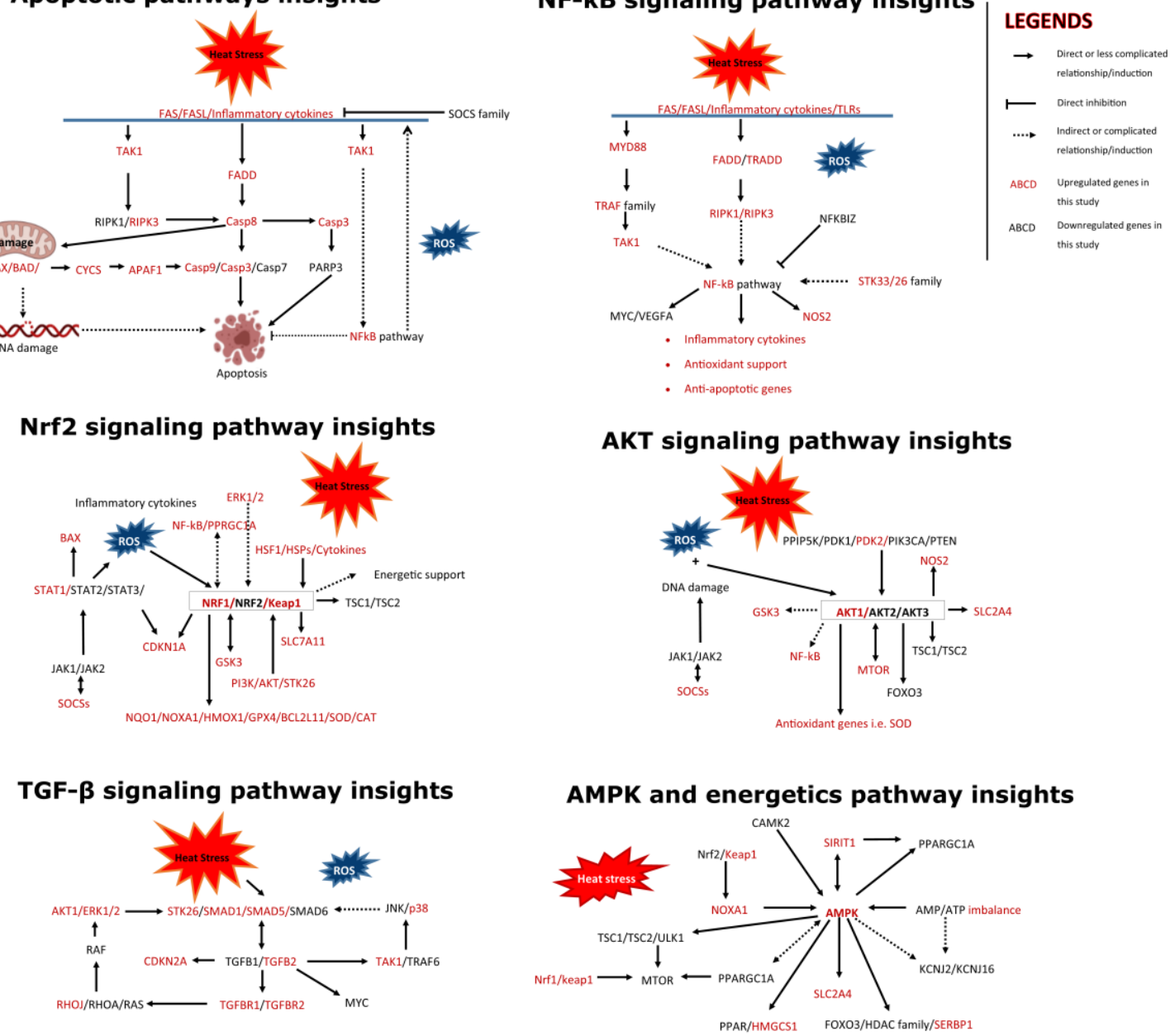

Figure 5. Various important cellular signaling pathways and the genes implicated in these pathways along with the regulation status of these genes in control versus heat-stress treatment of granulosa cells (upregulated genes or genes family are written in red color).

\subsection{Functional annotation of differentially expressed genes}

Further, DEGs were checked for gene ontology (GO) terms enrichment (Supplementary Table S4). All significant ( $p>0.05)$ GO terms details given as biological process (BP), cellular component (CC), and molecular function (MF) are presented in Figure 7. Whereas, top enriched genes in each of the functions of $\mathrm{BP}, \mathrm{CC}$, and MF terms along with their enrichment ratios are enlisted in Table 3. Genes TEK, VEGFA, ACTA2, and INSL3 have 
high enrichment ratio in more than one GO terms classification, while ACTA2 is the only upregulated DEG in the given DEGs.

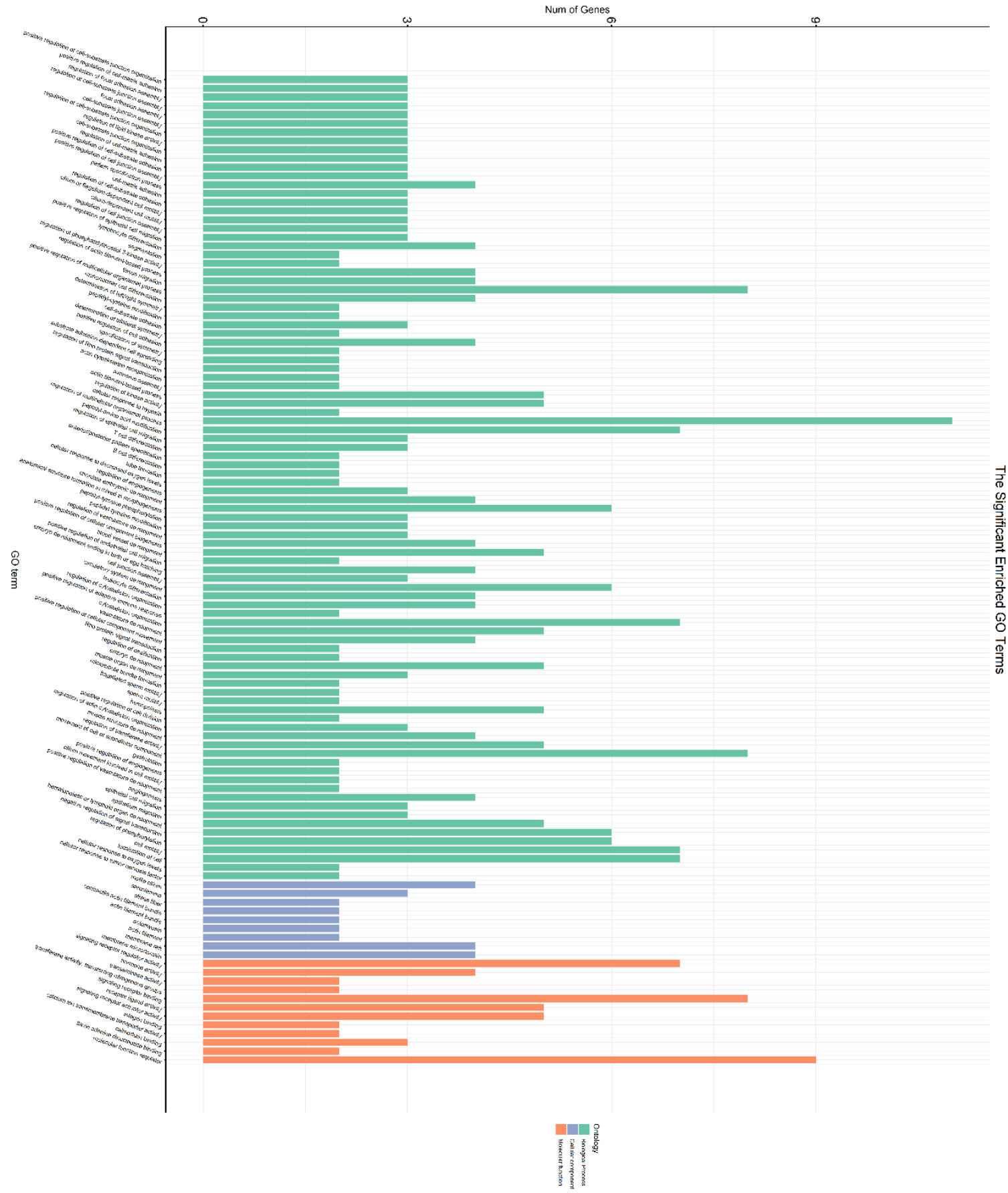

Figure 7. Detailed annotation of gene ontology (GO) terms $(p>0.05)$ of significant differentially expressed genes in control versus acute heat stress treatment groups. GO terms including biological process (BP), cellular components (CC), and molecular functions $(\mathrm{MF})$ enrichment ratios are given.

Table 3. Detailed annotation of gene ontology terms (GO) of significant differentially expressed genes (DEGs) in control versus acute heat stress treatment groups, was carried out. Top 10 DEGs enriched in various terms of biological process (BP) and top 5 enriched DEGs in cellular component (CC) and molecular function (MF) are detailed along their terms enrichment ratio and statistical detailing.

\begin{tabular}{ccccccc}
\hline \multicolumn{6}{c}{ Top 10 genes in biological process (BP) of gene ontology enrichment terms } \\
\hline Genes & TER & $\log$ FC & $\log$ CPM & & FDR & Description \\
\hline SFRP1 & 61 & -0.66 & 1.83 & 0.011 & secreted frizzled related protein 1 \\
\hline
\end{tabular}




\begin{tabular}{|c|c|c|c|c|c|}
\hline & \multirow[b]{2}{*}{0.001} & \multirow[b]{2}{*}{$\begin{array}{l}\text { TEK receptor tyrosine kinase } \\
\end{array}$} \\
\hline TEK & 54 & -0.97 & 1.22 & & \\
\hline VEGFA & 49 & -0.71 & 8.52 & $3 \mathrm{E}-16$ & vascular endothelial growth factor $\mathrm{A}$ \\
\hline$D R C 1$ & 13 & 0.94 & 0.17 & 0.016 & dynein regulatory complex subunit 1 \\
\hline LRRC6 & 15 & -0.70 & 1.39 & 0.016 & leucine rich repeat containing 6 \\
\hline LFNG & 15 & -0.62 & 4.30 & $8 \mathrm{E}-07$ & $\begin{array}{l}\text { LFNG O-fucosylpeptide 3-beta-N-acetylglucosaminyl- } \\
\text { transferase }\end{array}$ \\
\hline INSL3 & 10 & -1.40 & 0.40 & 3E-05 & Insulin Like 3 \\
\hline CATSPERD & 10 & -0.83 & 3.17 & 7E-09 & cation channel sperm associated auxiliary subunit delta \\
\hline NFKBIZ & 10 & -0.75 & 4.09 & 1E-09 & NFKB inhibitor zeta \\
\hline ACTA2 & 9 & 0.80 & 7.10 & $5 \mathrm{E}-37$ & "actin alpha 2, smooth muscle" \\
\hline \multicolumn{6}{|c|}{ Top 5 genes in cellular component (CC) of gene ontology enrichment terms } \\
\hline TEK & 7 & -0.97 & 1.22 & 0.001 & TEK receptor tyrosine kinase \\
\hline ACTA2 & 5 & 0.80 & 7.10 & $5 \mathrm{E}-37$ & "actin alpha 2, smooth muscle" \\
\hline SLC2A4 & 3 & 0.66 & 2.31 & 0.004 & solute carrier family 2 member 4 \\
\hline CAVIN4 & 3 & -0.67 & 1.21 & 0.023 & caveolae associated protein 4 \\
\hline TLR2 & 2 & 0.70 & 2.06 & 0.005 & toll like receptor 2 \\
\hline \multicolumn{6}{|c|}{ Top 5 genes in molecular function (MF) of gene ontology enrichment terms } \\
\hline IGF2 & 7 & -0.98 & 0.20 & 0.032 & insulin like growth factor 2 \\
\hline OXT & 6 & -1.51 & 0.13 & 0.0002 & oxytocin/neurophysin I prepropeptide \\
\hline$A P L N$ & 6 & -1.01 & 0.49 & 0.003 & apelin \\
\hline INSL3 & 6 & -1.40 & 0.40 & 3E-05 & Insulin Like 3 \\
\hline VEGFA & 5 & -0.71 & 8.52 & $3 \mathrm{E}-16$ & vascular endothelial growth factor A \\
\hline
\end{tabular}

TER; terms enrichment ratio (frequency of occurrence in various components) of genes, FDR; false discovery ratio.

\subsection{Protein-protein interaction (PPI) networks of DEGs under acute heat stress}

Function protein association network analysis of proteins coding DEGs comprising of various k-means clustering groups (STRING) with medium confidence score (0.4) are presented in Figure 8, while details are given in Supplementary table S5. Total number of nodes were 278, total number of edges (interactions) were 221, average local clustering coefficient of 0.324 , and PPI enrichment $p$-value stood at 4.93E-07. 


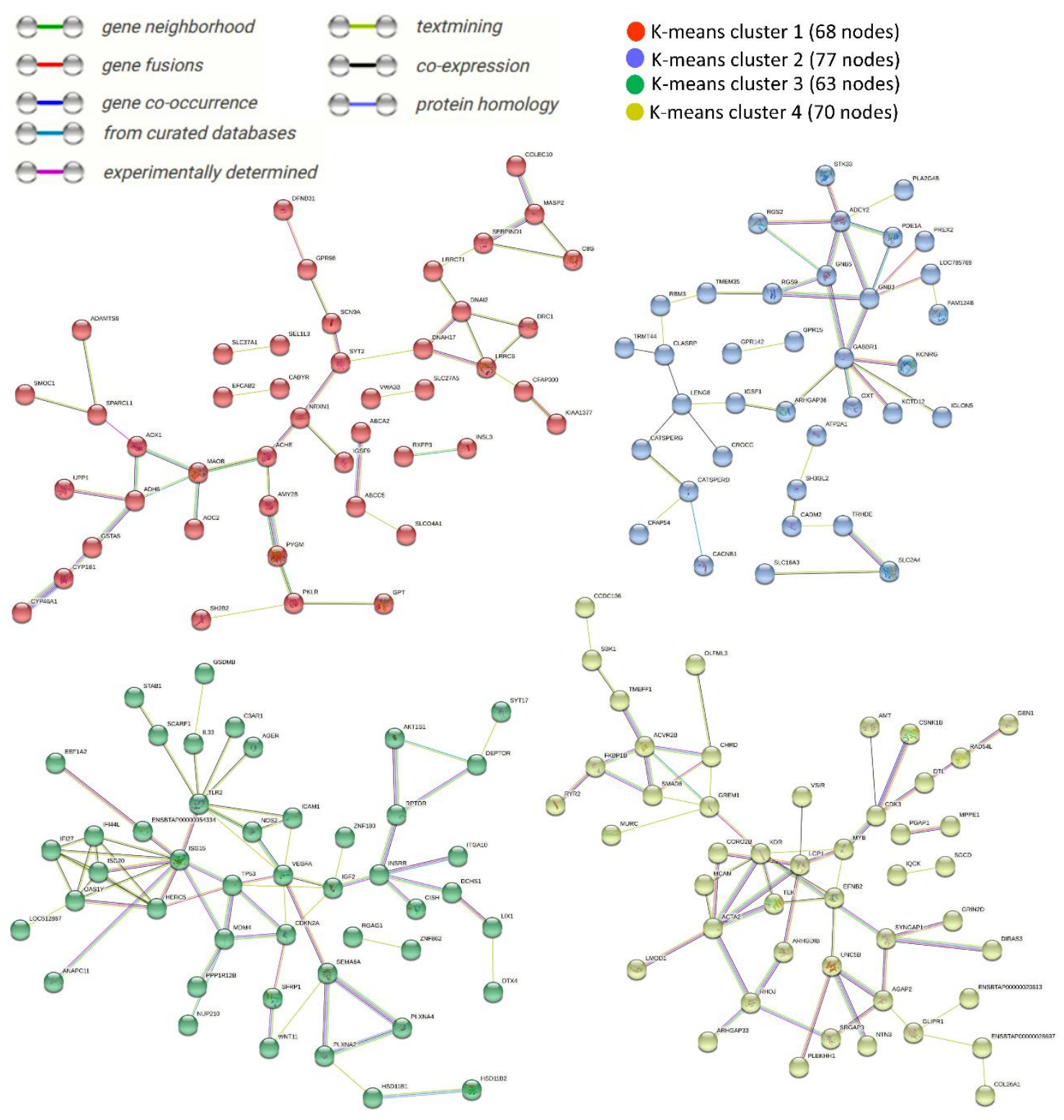

Figure 8. STRING interaction analysis of all differentially expressed genes (DEGs) in control verses heat-stressed granulosa cells. Interaction was performed with confidence score of 0.4 . String interaction map is divided in $4 \mathrm{k}$-means clusters with distinct set of DEGs. Nodes represents DEGs (protein coding genes) and lines between nodes refers to edges various sort of interactions denoted by different colors and defined through the legends present in the figure, stand-alone nodes lacking edges were removed.

Based on co-occurrence of "from curated database", "experimentally determined, and "text mining" interaction edges, SERPIND1, MASP2, AMY2B, PYGM, ADH6, GSTA5, CYP1B1, and CYP46A1 can be regarded as important nodes in k-means clustering 1 (68 nodes). Similarly, ADCY2, GNB5, GNB3, RGS9, GABBR1, and SLC2A4 can be regarded as important nodes in k-means clustering 2 (77 nodes). Genes ISG15, TP53, MDM4, CDKN2A, IGF2, AK1TS1, RPTOR, INSRP, SEMA6A, PLXN2A, and PLXNA4 can be regarded as important nodes in k-means clustering 3 (63 nodes). While, ACVR2B, FKBP1B, SMAD6, $K D R, A C T A 2, R H O J, U N C 5 B, S Y N G A P 1$, can be regarded as important nodes in k-means clustering 4 (70 nodes) in a similar way.

Additional full STRING network analysis with highest confidence score (0.9) was also carried out to narrow down the important interaction nodes (Figure 9). TP53, RPTOR, $F K B P 1 B, G N B 5$, and $A K T 1 S 1$ came out to be the important functional nodes with highest score. Whereas, SERPIND1, MASP2, AMY2B, PYGM, MAOB, ISG15, SEMA6A, and $P L X N A 2$ can be regarded as important nodes based on their centrality and edges. 


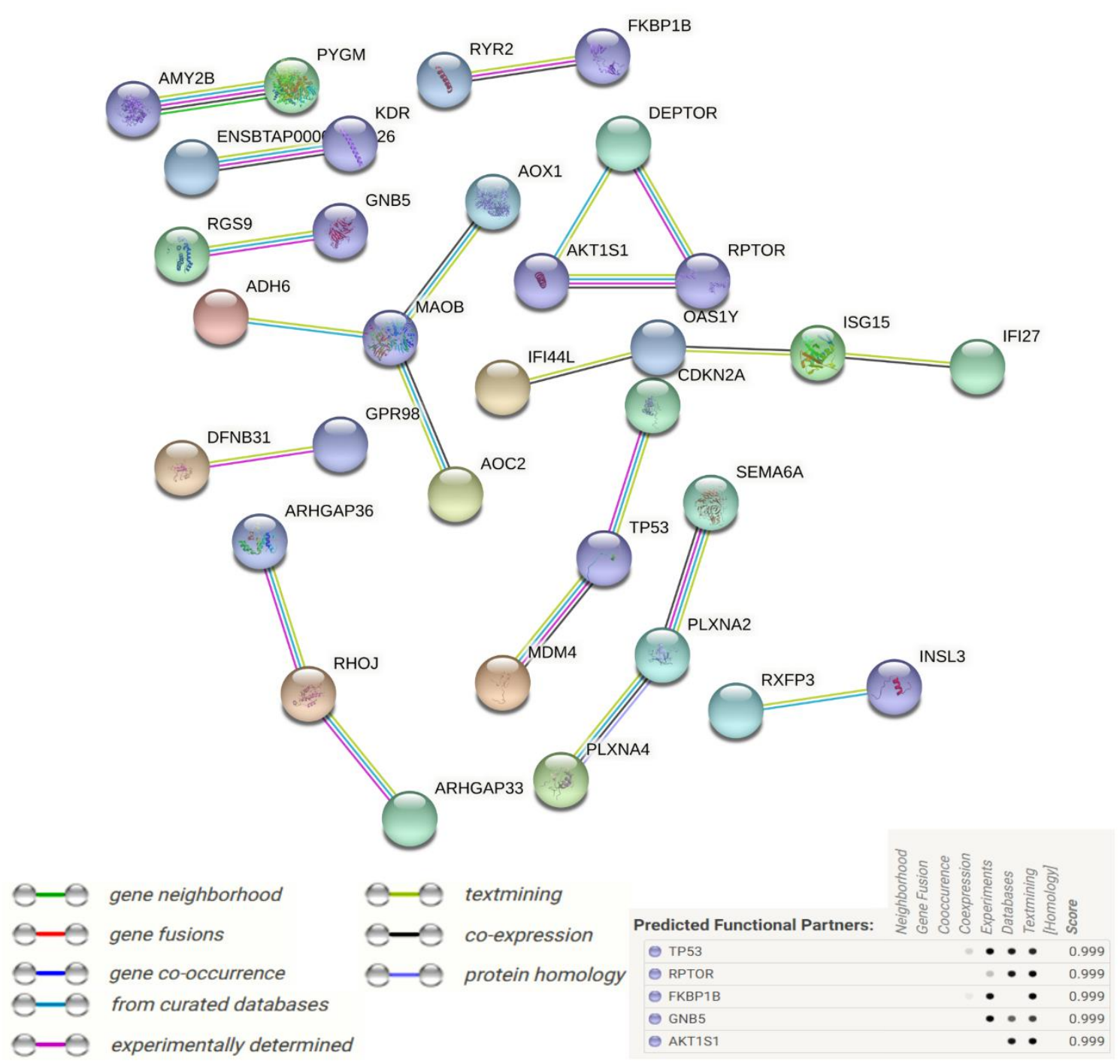

Figure 9. STRING interaction analysis of all differentially expressed genes in control verses heat-stressed granulosa cells. Interaction was performed with confidence score of 0.9. Nodes represents genes and lines between nodes refers to edges showing various sort of interactions denoted by different colors and defined through the legends present in the figure, stand-alone nodes lacking edges were removed. Important nodes with highest interaction scores of functional predictions are given in bottom right of the figure.

\section{Discussion}

Heat stress causes various adverse modifications at physiological and metabolic level in cows $[10,11,38]$. Timely conception of cows is imperative for profitable dairy and beef farming. However, occurrence of negative energy balance in postpartum cows causes mobilization of body fats into non-esterified fatty acids (NEFA) [39,40]. This phenomenon when accompanied with low body condition scores, clinical ketosis, decreased feed intake, fatty liver and other morbidities, leads to impairment of reproduction process [4143]. Summer times heat stress in the presence of negative energy balance and abnormal postpartum conditions [41-43] can cause changes in the blood metabolic profile extending effects towards ovarian follicles, developing oocyte and embryo [44,45]. Primary and preantral ovarian follicles are particularly susceptible to the adverse effects of heat stress $[13,23]$; the compromise of GCs in the follicles have negative impact on oocyte [20,46], leading to decline in their developmental competence [47]. Hence, we investigated the physical, biochemical, and transcriptome level changes in acute heat stressed GCs.

There was a significant decline in cell proliferation potential (cell senescence) in heat stress group compared to control group. Previous studies support this finding, where 
acute heat-stressed $\left(45^{\circ} \mathrm{C}\right) \mathrm{GCs}$ re-attained proliferation potential $48 \mathrm{hrs}$ post-treatment [32-34]. A 24 h delay of cell confluence achievement (at 72 h) observed in our study, can be attributed to different experimental methods and the species difference in these previous studies, as camels are thought to be relatively thermo-tolerant [32]. However, the trend of proliferation activity recovery of our GCs is following the results reported by Alemu et al. and Fu et al. $[17,48]$, where they reported post-heat stress recovery of GCs proliferation activity at $48 \mathrm{~h}$. GCs without heat stress treatment proliferated steadily, while heat stress group with immediate culture media change was relatively earlier to show positive proliferation change compared to the heat stress group with culture medium change at $48 \mathrm{~h}$. This phenomenon is interesting and need further investigation, a preliminary hypothesis may be drawn that heat stress is an energy intensive process, as supported by our previous review of literature studies $[49,50]$.

Acute heat stress in-vitro triggered accumulation of intracellular ROS and caused increased in apoptosis of GCs, previous studies on heat stress in GCs support these results are in accordance with the prior studies [18,51]. Previous studies show that post-heat stress intracellular ROS accumulation increases in a time dependent manner [17], while our study shows a substantial intracellular ROS accumulation within $10 \mathrm{hrs}$ of heat stress initiation. ROS production is a normal phenomenon occurring in the cells due to fundamental biological processes [52]. While higher ROS accumulation in the presence of a stress stimuli impairs cell antioxidant response elements (ARE), and causing oxidative stress [53]. Previous studies stress associates intercellular ROS to oxidative stress [54] and apoptosis in cells $[55,56]$. ROS-mediated oxidative stress induces bovine GCs apoptosis and compromises fertility in cows $[57,58]$. However, pathways and mechanisms underlying heat stress caused extreme oxidative stress and blunt ARE response causing apoptotic fate of the cells, are not completely understood. For instance, studies have reported the involvement of Nrf2 (nuclear factor (erythroid-derived 2)-like 2) pathway in upregulating the cellular antioxidant responses for the protection of cell apoptosis $[17,51,59]$.

Heat stressed GCs decreased the production of P4 and E2 hormones, as demonstrated previously $[17,18,48]$. This decline of steroidogenic activity of GCs can essentially be attributed to the downregulation of STAR, CYP11A1 [18] and mitochondrial damage due to ROS. However, this study found that majority of genes involved in cholesterol synthesis and homeostasis (like, HMGCS1, HMGCR, ACTA1, ACTA2, SLC25A1, SAOT1, AMPK, $S R D 5 A 3, D H D D S, F D P S)$ are upregulated in heat stress.

As shown earlier in this study, majority of genes primarily associated with cell damage (CYCS), inflammation (TLR2, TLR4, IL6, TNFRSF6B, TNFSF9) apoptosis initiation $(B A D, B A X, B A D, B A K 1, B I D)$ and execution (FADD, TRADD, and Caspases) are upregulated in heat stress, while conversely a large proportion of antioxidant and anti-apoptotic genes (HMOX1, NOXA1, NQO1, SIRIT1, BCL2L11, SOD, CAT, GPX4) are also upregulated. These variable and complicated phenomena indicates an evidence of intricate "biological fight" in heat-stressed GCs, and essentially explain the observation of post-heat stress transient senescence of GCs found in this and previous study [32].

In the events of cellular stress, the Nrf2 pathway is involved in complex up regulatory functions related to cell metabolism in conjunction with NF- $\kappa \mathrm{B}$ (nuclear factor kappa light chain enhancer of activated B cells) [60,61], PI3K/AKT/mTOR [39,62,63], and AMPK signaling pathways [64]. Evidence of high ROS, upregulation of inflammatory cytokines, ERK1/2, AKT1, KEAP1, and NRF1 indicates induction of Nrf2 pathway, which is augmented by antioxidant and anti-apoptotic genes. Genes GSK3A, GSK3B, and serine threonine kinases like STK26 and STK33 also evidences the activity of Nrf2 pathway. While the upregulation of $C D K N 2 A$ is also interesting, which augments the repression of transcription activity by Nrf2 pathway in heat-stressed GCs [59]. Gene SLC2A4 encoding GLUT4 was upregulated in heat stress, however, we propose that Nrf2 pathway cannot be solely implicated in the GC's bioenergetics based protective responses against thermally driven oxidative stress. While the complex role of the transforming growth factor- $\beta$ (TGF- $\beta$ ) pathway is also important in this context, which is involved in signaling mechanisms related to upregulation of NF- $\kappa \mathrm{B}$ and inducing apoptosis through cell cycle arrest $[65,66]$. The 
most important evidence of cell cycle arrest in heat stressed GCs can be explained by our finding of down regulation of $M Y C$ and upregulated $C D K N 2 A$ and $C D K N 1 A$, which may lead to apoptosis. There was an evidence of non-canonical induction of TGF- $\beta$ signaling pathway as indicated by downregulation of SMAD6 and upregulation of RHOJ, MAPK1, and $A K T 1$ in this study [67]. Regarding the MAPK signaling, upregulation of MAP3K7 (TAK1) and MAPK14 (p38) [68], and down regulation of MAPK8 is of particular importance [69], as evidenced in this study and may contribute to the apoptosis of heatstressed GCs. Regarding the AMPK signaling pathway in this study, it is characterized by down regulation of ATP genes family and PPARGC1A, and upregulation of SIRIT1, GLUT4, HMGCS1, and SERBP1[64,70].

GCs plays an integral role in ovaries through its steroidogenic roles and oocyte development role [15,16]. Heat stress and its adverse effects on GCs have been implicated as one of the cause of fertility decline mammals [13,18,22]. In the previous section of discussion, we elaborated the effects of acute heat stress on the physical parameters of GCs. While at the same time we tried to elaborate brief insights about the pattern of major biological pathways and their regulation. Out of 12385 true RNA reads from the global transcriptomic comparison of control and acute heat-stressed GCs, 330 significant DEGs were determined through post-analyses. Majority of DEGs were downregulated (225), indicating adverse effect of acute heat stress on the transcriptome of GCs. Going through the list of top 20 up and down regulated DEGs, RBM3 appeared as the most significant upregulated DEG, this gene being a cancer biomarker is also shown to promote DNA integrity and promote cellular homeostasis through complex signaling [71]. GCs are obviously overstressed and the presence of various BMP antagonist, cell-structural remodeling, regulation of cell proliferation, receptors, ligands and membrane channels related genes explains a major part of upregulated DEGs. Similarly, majority of top 20 downregulated DEGs relates to cell-structural disturbance, lack of cell proliferation potential, and genes related to the energetic homeostasis of cell. Heat shock proteins family response in the presence of upregulated HSF1 was also relatively blunted in response to acute heat stress, with only few members like HSPA12A, HSPA9, HSPB6, and HSPBP1 being upregulated genes. Upon the manual query of the highly conserved and common protein-protein interaction motifs, the Ankyrin (ANK) family and ANK repeat containing domain genes are also downregulated in response to heat stress. This phenomenon explains that the effects of acute heat stress on GCs are extensive. While the details of pro-apoptotic, anti-apoptotic and antioxidant genes have been discussed earlier, where there is evidence of strong ongoing antioxidant response in GCs after acute heat stress. KEGG functional pathway analysis show an enrichment of pathways, like VEGF and TGF- $\beta$ signaling, showing the disturbance of cellular transcriptional and proliferation. While various amino acids metabolism associated pathways enrichment show the evidence of proteins breakdown and decline of cellular energetics homeostasis. While the remaining KEGG enriched pathways nodes towards the intercellular structures breakdown and disturbance. These observations are augmented by the downregulated status of the entire list of top DEGs enriched in all KEGG pathways. Majority of GO annotations enrichment were observed in the BP enrichment terms, where except $A C T A 2$, all DEGs with highest enrichment ratios are downregulated in response to acute heat stress. While along with $A C A T 2$, only two other upregulated DEGs are TLR2 and SLC2A4, in CC and MF of GO terms enrichment. Earlier studies involving acute heat stress in bovine skeletal muscles [39] and GCs [72] have reported altered metabolism and insulin signaling, lack of anabolic activities, and extensive reshuffling in the bioenergetics mechanisms involving multiple signaling pathways. Heat stress and associated oxidative stress is shown to lead to upregulated inflammatory response $[73,74]$, while inflammation is energy intensive and leads to metabolic imbalance $[75,76]$. Similarly, a previous study involving acute and chronic heat-stressed GCs, evident changes in the cell structure and morphology were observed [32]. Therefore, among these DEGs, TLR2 can be taken as a representative of inflammatory response and cytokine sig- 
naling upregulation, $S L C 2 A 4$ as a representative of cellular energetic support mechanisms, and $A C T A 2$ as the representative of resort of maintaining the cellular structural integrity in response to heat stress.

\section{Conclusions}

Upon the infliction of in-vitro acute heat stress, GCs suffers from decreased cell viability, high oxidative stress, and increase in the apoptosis rate. Steroidogenic potential of GCs declines, in spite of the evidence of normal cellular cholesterol metabolism. A large number of antioxidant and anti-apoptotic genes remained upregulated, in spite of a strong evidence of upregulated pro-apoptotic and apoptotic genes. There is extensive interplay among all major cell signaling pathways, where the evidence suggests repression of cell transcriptional and proliferation activity, and cellular "resort" of averting the effects of heat stress through remodeling of cellular structural proteins and energetic homeostasis. Our RNA-seq approach gave novel insights into the biological mechanisms and transcriptional activity of GCs exposed to acute heat stress and opens gates of further research in these type of cell-stress stimuli interactions.

Supplementary Materials: The following are available online at www.mdpi.com/xxx/s1, Figure S1: RNA-seq read counts of heat stress and control groups (3 replicate each) are distinctly different from each other as shown in principal components analysis and dendrogram clustering structure, Table S1: List of all differentially expressed gene reads along with their statistics parameters, found in control versus heat stressed granulosa cells; Table S2: List of all significant differentially expressed (fold change of ysis of differentially expressed genes (DEGs) in response to heat stress granulosa cells: All the significantly $(\mathrm{p}<0.05)$ re; Table S3: Kyoto encyclopedia of genes and genomes (KEGG) based pathway analysis of differentially expressed genes (DEGs) in response to heat stress granulosa cells: All the significantly $(\mathrm{p}<0.05)$ regulated pathways and DEGs enrichment ratios are illustrated; Table S4: Detailed annotation of gene ontology $(\mathrm{GO})$ terms ( $p>0.05)$ of significant differentially expressed genes in control versus acute heat stress treatment groups. GO terms including biological process (BP), cellular components (CC), and molecular functions (MF) enrichment ratios are given; Table S5: List containing differentially expressed genes involved in 4 kmeans clustrings of STRING interaction network analysis.

Author Contributions: A.S carried out experimentation, analysis, and writing. H.L and L.H helped in analysis and writing. Y.W and H.Z were involved in the conception, review, supervision of the project and validation of the manuscript. All authors approved the final version and consented to publication.

Funding: This work was possible due to the financial assistance from the following projects; China Agriculture Research System of MOF and MARA, the Program for Changjiang Scholar and Innovation Research Team in University (IRT-15R62).

Data Availability Statement: All the pertinent data including that of RNA-seq is presented in the manuscript and associated supplementary files.

Conflicts of Interest: Authors declare no conflict of interests. Funders had no role in the design of the study; in the collection, analyses, or interpretation of data; in the writing of the manuscript, or in the decision to publish. 


\section{References}

1. Sherwood, S.C.; Huber, M. An adaptability limit to climate change due to heat stress. Proc. Natl. Acad. Sci. U. S. A. 2010, 107, doi:10.1073/pnas.0913352107.

2. Zhao, C.; Liu, B.; Piao, S.; Wang, X.; Lobell, D.B.; Huang, Y.; Huang, M.; Yao, Y.; Bassu, S.; Ciais, P.; et al. Temperature increase reduces global yields of major crops in four independent estimates. Proc. Natl. Acad. Sci. U. S. A. 2017, 114, doi:10.1073/pnas.1701762114.

3. Kovats, R.S.; Hajat, S. Heat stress and public health: A critical review. In Proceedings of the Annual Review of Public Health; 2008; Vol. 29.

4. Das, R.; Sailo, L.; Verma, N.; Bharti, P.; Saikia, J.; Imtiwati; Kumar, R. Impact of heat stress on health and performance of dairy animals: A review. Vet. World 2016, 9, 260-268.

5. Collier, R.J.; Collier, J.L. Environmental Physiology of Livestock; 2012;

6. Sammad, A.; Luo, H.; Qiu, W.; Galindez, J.M.; Wang, Y.; Guo, G.; Huang, X.; Wang, Y. Automated monitoring of seasonal and diurnal variation of rumination behaviour: Insights into thermotolerance management of Holstein cows. Biosyst. Eng. 2021, doi:10.1016/J.BIOSYSTEMSENG.2021.12.002.

7. Ray, D.; Correa-Calderon, A.; Armstrong, D.; Enns, M.; DeNise, S.; Howison, C. Thermoregulatory responses of Holstein and Brown Swiss Heat-Stressed dairy cows to two different cooling systems. Int. J. Biometeorol. 2004, 48, 142-148, doi:10.1007/s00484003-0194-y.

8. $\quad$ Asseng, S.; Spänkuch, D.; Hernandez-Ochoa, I.M.; Laporta, J. The upper temperature thresholds of life. Lancet Planet. Heal. 2021,5 .

9. Pinto, S.; Hoffmann, G.; Ammon, C.; Amon, T. Critical THI thresholds based on the physiological parameters of lactating dairy cows. J. Therm. Biol. 2020, 88, 102523, doi:10.1016/J.JTHERBIO.2020.102523.

10. Sammad, A.; Wang, Y.J.; Umer, S.; Lirong, H.; Khan, I.; Khan, A.; Ahmad, B.; Wang, Y. Nutritional physiology and biochemistry of dairy cattle under the influence of heat stress: Consequences and opportunities. Animals 2020, 10.

11. Sammad, A.; Khan, M.Z.; Abbas, Z.; Hu, L.; Ullah, Q.; Wang, Y.; Zhu, H.; Wang, Y. Major Nutritional Metabolic Alterations Influencing the Reproductive System of Postpartum Dairy Cows. Metab. 2022, Vol. 12, Page 60 2022, 12, 60, doi:10.3390/METABO12010060.

12. Hansen, P.J. Embryonic mortality in cattle from the embryo's perspective. J. Anim. Sci. 2002, 80, doi:10.2527/animalsci2002.80e-suppl_2e33x.

13. Sammad, A.; Umer, S.; Shi, R.; Zhu, H.; Zhao, X.; Wang, Y. Dairy cow reproduction under the influence of heat stress. J. Anim. Physiol. Anim. Nutr. (Berl). 2020, 104, doi:10.1111/jpn.13257.

14. Destaw, W.M.; Kefyalew, A.W. Evaluation of the reproductive performance of Holstein Friesian dairy cows in Alage ATVET college, Ethiopia. Int. J. Livest. Prod. 2018, 9, 131-139, doi:10.5897/IJLP2018.0469.

15. Jahromi, B.N.; Mosallanezhad, Z.; Matloob, N.; Davari, M.; Ghobadifar, M.A. The potential role of granulosa cells in the maturation rate of immature human oocytes and embryo development: A co-culture study. Clin. Exp. Reprod. Med. 2015, 42, doi:10.5653/cerm.2015.42.3.111.

16. Diaz, F.J.; Wigglesworth, K.; Eppig, J.J. Oocytes determine cumulus cell lineage in mouse ovarian follicles. J. Cell Sci. 2007, 120, doi:10.1242/jcs.000968.

17. Alemu, T.W.; Pandey, H.O.; Salilew Wondim, D.; Gebremedhn, S.; Neuhof, C.; Tholen, E.; Holker, M.; Schellander, K.; Tesfaye, D. Oxidative and endoplasmic reticulum stress defense mechanisms of bovine granulosa cells exposed to heat stress. Theriogenology 2018, 110, doi:10.1016/j.theriogenology.2017.12.042.

18. Khan, A.; Dou, J.; Wang, Y.; Jiang, X.; Khan, M.Z.; Luo, H.; Usman, T.; Zhu, H. Evaluation of heat stress effects on cellular and transcriptional adaptation of bovine granulosa cells. J. Anim. Sci. Biotechnol. 2020111 2020, 11, 1-20, doi:10.1186/S40104-019-04088.

19. Liu, H.L.; Liu, D.; Ding, G.R.; Liao, P.F.; Zhang, J.W. Hypoxia-inducible factor- $1 \alpha$ and Wnt/ $\beta$-catenin signaling pathways promote the invasion of hypoxic gastric cancer cells. Mol. Med. Rep. 2015, 12, doi:10.3892/mmr.2015.3812.

20. Roth, Z. Heat stress reduces maturation and developmental capacity in bovine oocytes. Reprod. Fertil. Dev. 2021, 33, doi:10.1071/RD20213.

21. Roth, Z.; Meiden, R.; Braw-Tal, R.; Wolfenson, D. Immediate and delayed effects of heat stress on follicular development and its association with plasma FSH and inhibin concentration in cows. J. Reprod. Fertil. 2000, 120, doi:10.1530/jrf.0.1200083.

22. Gaskins, A.J.; Mínguez-Alarcón, L.; VoPham, T.; Hart, J.E.; Chavarro, J.E.; Schwartz, J.; Souter, I.; Laden, F. Impact of ambient temperature on ovarian reserve. Fertil. Steril. 2021, 116, doi:10.1016/j.fertnstert.2021.05.091.

23. Wolfenson, D.; Roth, Z. Impact of heat stress on cow reproduction and fertility. Anim. Front. 2019, 9, doi:10.1093/af/vfy027.

24. Tseng, J.K.; Chen, C.H.; Chou, P.C.; Yeh, S.P.; Ju, J.C. Influences of follicular size on parthenogenetic activation and in vitro heat shock on the cytoskeleton in cattle oocytes. Reprod. Domest. Anim. 2004, 39, doi:10.1111/j.1439-0531.2004.00493.x.

25. Shehab-El-Deen, M.A.M.M.; Leroy, J.L.M.R.; Fadel, M.S.; Saleh, S.Y.A.; Maes, D.; Van Soom, A. Biochemical changes in the follicular fluid of the dominant follicle of high producing dairy cows exposed to heat stress early post-partum. Anim. Reprod. Sci. 2010, 117, doi:10.1016/j.anireprosci.2009.04.013. 
26. Baumgard, L.H.; Wheelock, J.B.; Sanders, S.R.; Moore, C.E.; Green, H.B.; Waldron, M.R.; Rhoads, R.P. Postabsorptive carbohydrate adaptations to heat stress and monensin supplementation in lactating Holstein cows1. J. Dairy Sci. 2011, 94, 5620-5633, doi:10.3168/jds.2011-4462.

27. Shin, E.K.; Jeong, J.K.; Choi, I.S.; Kang, H.G.; Hur, T.Y.; Jung, Y.H.; Kim, I.H. Relationships among ketosis, serum metabolites, body condition, and reproductive outcomes in dairy cows. Theriogenology 2015, 84, doi:10.1016/j.theriogenology.2015.03.014.

28. Leroy, J.L.M.R.; Vanholder, T.; Mateusen, B.; Christophe, A.; Opsomer, G.; de Kruif, A.; Genicot, G.; Van Soom, A. Nonesterified fatty acids in follicular fluid of dairy cows and their effect on developmental capacity of bovine oocytes in vitro. Reproduction 2005, 130, doi:10.1530/rep.1.00735.

29. Bromfield, J.J.; Sheldon, I.M. Lipopolysaccharide initiates inflammation in bovine granulosa cells via the TLR4 pathway and perturbs oocyte meiotic progression in vitro. Endocrinology 2011, 152, doi:10.1210/en.2011-1124.

30. Paes, V.M.; Vieira, L.A.; Correia, H.H.V.; Sa, N.A.R.; Moura, A.A.A.; Sales, A.D.; Rodrigues, A.P.R.; Magalhães-Padilha, D.M.; Santos, F.W.; Apgar, G.A.; et al. Effect of heat stress on the survival and development of in vitro cultured bovine preantral follicles and on in vitro maturation of cumulus-oocyte complex. Theriogenology 2016, 86, 994-1003, doi:10.1016/J.THERIOGENOLOGY.2016.03.027.

31. Vanholder, T.; Leroy, J.L.M.R.; Van Soom, A.; Opsomer, G.; Maes, D.; Coryn, M.; De Kruif, A. Effect of non-esterified fatty acids on bovine granulosa cell steroidogenesis and proliferation in vitro. Anim. Reprod. Sci. 2005, 87, doi:10.1016/j.anireprosci.2004.09.006.

32. Saadeldin, I.M.; Swelum, A.A.A.; Elsafadi, M.; Mahmood, A.; Osama, A.; Shikshaky, H.; Alfayez, M.; Alowaimer, A.N.; Magdeldin, S. Thermotolerance and plasticity of camel somatic cells exposed to acute and chronic heat stress. J. Adv. Res. 2020, 22, 105-118, doi:10.1016/J.JARE.2019.11.009.

33. Saadeldin, I.M.; Swelum, A.A.A.; Elsafadi, M.; Mahmood, A.; Alfayez, M.; Alowaimer, A.N. Differences between the tolerance of camel oocytes and cumulus cells to acute and chronic hyperthermia. J. Therm. Biol. 2018, 74, 47-54, doi:10.1016/J.JTHERBIO.2018.03.014.

34. Fu, Y.; He, C.-J.; Ji, P.-Y.; Zhuo, Z.-Y.; Tian, X.-Z.; Wang, F.; Tan, D.-X.; Liu, G.-S. Effects of Melatonin on the Proliferation and Apoptosis of Sheep Granulosa Cells under Thermal Stress. Int. J. Mol. Sci. 2014, Vol. 15, Pages 21090-21104 2014, 15, 21090-21104, doi:10.3390/IJMS151121090.

35. Rio, D.C.; Ares, M.; Hannon, G.J.; Nilsen, T.W. Purification of RNA using TRIzol (TRI Reagent). Cold Spring Harb. Protoc. 2010, 5, doi:10.1101/pdb.prot5439.

36. Chen, S.; Zhou, Y.; Chen, Y.; Gu, J. Fastp: An ultra-fast all-in-one FASTQ preprocessor. In Proceedings of the Bioinformatics; 2018; Vol. 34.

37. McCarthy, D.J.; Chen, Y.; Smyth, G.K. Differential expression analysis of multifactor RNA-Seq experiments with respect to biological variation. Nucleic Acids Res. 2012, 40, doi:10.1093/nar/gks042.

38. Collier, R.J.; Baumgard, L.H.; Zimbelman, R.B.; Xiao, Y. Heat stress: physiology of acclimation and adaptation. Anim. Front. 2019, 9, 12-19, doi:10.1093/af/vfy031.

39. Ganesan, S.; Summers, C.M.; Pearce, S.C.; Gabler, N.K.; Valentine, R.J.; Baumgard, L.H.; Rhoads, R.P.; Selsby, J.T. Shortterm heat stress altered metabolism and insulin signaling in skeletal muscle. J. Anim. Sci. 2018, 96, doi:10.1093/jas/skx083.

40. Chapinal, N.; LeBlanc, S.J.; Carson, M.E.; Leslie, K.E.; Godden, S.; Capel, M.; Santos, J.E.P.; Overton, M.W.; Duffield, T.F. Herd-level association of serum metabolites in the transition period with disease, milk production, and early lactation reproductive performance. J. Dairy Sci. 2012, 95, doi:10.3168/jds.2011-5132.

41. Dobson, H.; Smith, R.; Royal, M.; Knight, C.; Sheldon, I. The high-producing dairy cow and its reproductive performance. Reprod. Domest. Anim. 2007, 42 Suppl 2, 17-23, doi:10.1111/j.1439-0531.2007.00906.x.

42. Vergara, C.F.; Döpfer, D.; Cook, N.B.; Nordlund, K. V.; McArt, J.A.A.; Nydam, D. V.; Oetzel, G.R. Risk factors for postpartum problems in dairy cows: Explanatory and predictive modeling. J. Dairy Sci. 2014, 97, 4127-4140, doi:10.3168/jds.2012-6440.

43. Miqueo, E.; Chiarle, A.; Giuliodori, M.J.; Relling, A.E. Association between prepartum metabolic status and resumption of postpartum ovulation in dairy cows. Domest. Anim. Endocrinol. 2019, 69, doi:10.1016/j.domaniend.2019.04.005.

44. Al-Katanani, Y.M.; Webb, D.W.; Hansen, P.J. Factors affecting seasonal variation in 90-day nonreturn rate to first service in lactating Holstein cows in a hot climate. J. Dairy Sci. 1999, 82, doi:10.3168/jds.S0022-0302(99)75516-5.

45. Kamil Siatka, Anna Sawa, D.P.; Mariusz Bogucki, S.K.-C. Factors affecting first insemination success in Polish HolsteinFresian cows. Anim. Sci. Pap. Reports 2018, 36, 275-285.

46. Abdelnour, S.A.; Swelum, A.A.; Abd El-Hack, M.E.; Khafaga, A.F.; Taha, A.E.; Abdo, M. Cellular and functional adaptation to thermal stress in ovarian granulosa cells in mammals. J. Therm. Biol. 2020, 92.

47. Gendelman, M.; Aroyo, A.; Yavin, S.; Roth, Z. Seasonal effects on gene expression, cleavage timing, and developmental competence of bovine preimplantation embryos. Reproduction 2010, 140, doi:10.1530/REP-10-0055.

48. $\quad$ Fu, Y.; He, C.-J.; Ji, P.-Y.; Zhuo, Z.-Y.; Tian, X.-Z.; Wang, F.; Tan, D.-X.; Liu, G.-S. Effects of Melatonin on the Proliferation and Apoptosis of Sheep Granulosa Cells under Thermal Stress. Int. J. Mol. Sci. 2014, Vol. 15, Pages 21090-21104 2014, 15, 21090-21104, doi:10.3390/IJMS151121090.

49. Sammad, A.; Wang, Y.J.; Umer, S.; Lirong, H.; Khan, I.; Khan, A.; Ahmad, B.; Wang, Y. Nutritional Physiology and Biochemistry of Dairy Cattle under the Influence of Heat Stress: Consequences and Opportunities. Animals 2020, 10, 793, doi:10.3390/ani10050793.

50. Abbas, Z.; Sammad, A.; Hu, L.; Fang, H.; Xu, Q.; Wang, Y. Glucose metabolism and dynamics of facilitative glucose transporters (Gluts) under the influence of heat stress in dairy cattle. Metabolites 2020, 10. 
51. Wang, Y.; Yang, C.; Elsheikh, N.A.H.; Li, C.; Yang, F.; Wang, G.; Li, L. HO-1 reduces heat stress-induced apoptosis in bovine granulosa cells by suppressing oxidative stress. Aging (Albany. NY). 2019, 11, doi:10.18632/aging.102136.

52. Soto, P.; Smith, L.C. BH4 peptide derived from Bcl-xL and Bax-inhibitor peptide suppresses apoptotic mitochondrial changes in heat stressed bovine oocytes. Mol. Reprod. Dev. 2009, 76, doi:10.1002/mrd.20986.

53. Abdelnour, S.A.; Abd El-Hack, M.E.; Khafaga, A.F.; Arif, M.; Taha, A.E.; Noreldin, A.E. Stress biomarkers and proteomics alteration to thermal stress in ruminants: A review. J. Therm. Biol. 2019, 79.

54. Azad, M.A.K.; Kikusato, M.; Sudo, S.; Amo, T.; Toyomizu, M. Time course of ROS production in skeletal muscle mitochondria from chronic heat-exposed broiler chicken. Comp. Biochem. Physiol. - A Mol. Integr. Physiol. 2010, 157, doi:10.1016/j.cbpa.2010.07.011.

55. Gu, Z.T.; Li, L.; Wu, F.; Zhao, P.; Yang, H.; Liu, Y.S.; Geng, Y.; Zhao, M.; Su, L. Heat stress induced apoptosis is triggered by transcription-independent p53, Ca2+ dyshomeostasis and the subsequent Bax mitochondrial translocation. Sci. Reports 201551 2015, 5, 1-15, doi:10.1038/srep11497.

56. Hou, C.H.; Lin, F.L.; Hou, S.M.; Liu, J.F. Hyperthermia induces apoptosis through endoplasmic reticulum and reactive oxygen species in human Osteosarcoma cells. Int. J. Mol. Sci. 2014, 15, doi:10.3390/ijms151017380.

57. Guérin, P.; El Mouatassim, S.; Ménézo, Y. Oxidative stress and protection against reactive oxygen species in the pre-implantation embryo and its surroundings. Hum. Reprod. Update 2001, 7.

58. Zhang, X.-Y.; Xiong, Y.-M.; Tan, Y.-J.; Wang, L.; Li, R.; Zhang, Y.; Liu, X.-M.; Lin, X.-H.; Jin, L.; Hu, Y.-T.; et al. Melatonin rescues impaired penetration ability of human spermatozoa induced by mitochondrial dysfunction. Reproduction 2019, 158, 465-475, doi:10.1530/REP-19-0231.

59. Villeneuve, N.F.; Sun, Z.; Chen, W.; Zhang, D.D. Nrf2 and p21 regulate the fine balance between life and death by controlling ROS levels. Cell Cycle 2009, 8 .

60. Pedruzzi, L.M.; Stockler-Pinto, M.B.; Leite, M.; Mafra, D. Nrf2-keap1 system versus NF-kB: The good and the evil in chronic kidney disease? Biochimie 2012, 94, 2461-2466, doi:10.1016/J.BIOCHI.2012.07.015.

61. Wardyn, J.D.; Ponsford, A.H.; Sanderson, C.M. Dissecting molecular cross-talk between Nrf2 and NF- $\kappa B$ response pathways. Biochem. Soc. Trans. 2015, 43, 621-626, doi:10.1042/BST20150014.

62. Hambright, H.G.; Meng, P.; Kumar, A.P.; Ghosh, R. Inhibition of PI3K/AKT/mTOR axis disrupts oxidative stress-mediated survival of melanoma cells. Oncotarget 2015, 6, doi:10.18632/oncotarget.3131.

63. Reddy, N.M.; Potteti, H.R.; Vegiraju, S.; Chen, H.J.; Tamatam, C.M.; Reddy, S.P. PI3K-AKT Signaling via Nrf2 Protects against Hyperoxia-Induced Acute Lung Injury, but Promotes Inflammation Post-Injury Independent of Nrf2 in Mice. PLoS One 2015, 10, e0129676, doi:10.1371/JOURNAL.PONE.0129676.

64. Cantó, C.; Auwerx, J. PGC-1 $\alpha$, SIRT1 and AMPK, an energy sensing network that controls energy expenditure. Curr. Opin. Lipidol. 2009, 20, 98-105, doi:10.1097/MOL.0B013E328328D0A4.

65. Li, Z.Y.; Chen, Z.L.; Zhang, T.; Wei, C.; Shi, W.Y. TGF- $\beta$ and NF- $\kappa B$ signaling pathway crosstalk potentiates corneal epithelial senescence through an RNA stress response. Aging (Albany. NY). 2016, 8, doi:10.18632/aging.101050.

66. Tominaga, K.; Suzuki, H.I. TGF- $\beta$ signaling in cellular senescence and aging-related pathology. Int. J. Mol. Sci. $2019,20$.

67. Zhang, Y.E. Non-Smad pathways in TGF- $\beta$ signaling. Cell Res. 2009, 19.

68. Yu-Wei, D.; Li, Z. sheng; Xiong, S. min; Huang, G.; Luo, Y. fei; Huo, T. ying; Zhou, M. hua; Zheng, Y. wei Paclitaxel induces apoptosis through the TAK1-JNK activation pathway. FEBS Open Bio 2020, 10, doi:10.1002/2211-5463.12917.

69. Jia, Y.; Castellanos, J.; Wang, C.; Sinha-Hikim, I.; Lue, Y.; Swerdloff, R.S.; Sinha-Hikim, A.P. Mitogen-activated protein kinase signaling in male germ cell apoptosis in the rat. Biol. Reprod. 2009, 80, doi:10.1095/biolreprod.108.072843.

70. Mihaylova, M.M.; Shaw, R.J. The AMP-activated protein kinase (AMPK) signaling pathway coordinates cell growth, autophagy, \& metabolism. Nat. Cell Biol. 2011, 13.

71. Ehlén, Å.; Nodin, B.; Rexhepaj, E.; Brändstedt, J.; Uhlén, M.; Alvarado-Kristensson, M.; Pontén, F.; Brennan, D.J.; Jirström, K. RBM3-regulated genes promote DNA integrity and affect clinical outcome in epithelial ovarian cancer. Transl. Oncol. 2011, 4, doi:10.1593/tlo.11106.

72. Sammad, A.; Hu, L.; Luo, H.; Abbas, Z.; Umer, S.; Zhao, S.; Xu, Q.; Khan, A.; Wang, Y.; Zhu, H.; et al. Investigation of Metabolome Underlying the Biological Mechanisms of Acute Heat Stressed Granulosa Cells. Int. J. Mol. Sci. 2022, Vol. 23, Page 2146 2022, 23, 2146, doi:10.3390/IJMS23042146.

73. Lauridsen, C. From oxidative stress to inflammation: Redox balance and immune system. In Proceedings of the Poultry Science; 2019; Vol. 98.

74. Hansson, E.; Glaser, J.; Jakobsson, K.; Weiss, I.; Wesseling, C.; Lucas, R.A.I.; Wei, J.L.K.; Ekström, U.; Wijkström, J.; Bod in, T.; et al. Pathophysiological mechanisms by which heat stress potentially induces kidney inflammation and chronic kidney disease in sugarcane workers. Nutrients 2020, 12, doi:10.3390/nu12061639.

75. Könner, A.C.; Brüning, J.C. Toll-like receptors: Linking inflammation to metabolism. Trends Endocrinol. Metab. $2011,22$.

76. Chimenti, M.S.; Triggianese, P.; Conigliaro, P.; Candi, E.; Melino, G.; Perricone, R. The interplay between inflammation and metabolism in rheumatoid arthritis. Cell Death Dis. 2015, 6. 